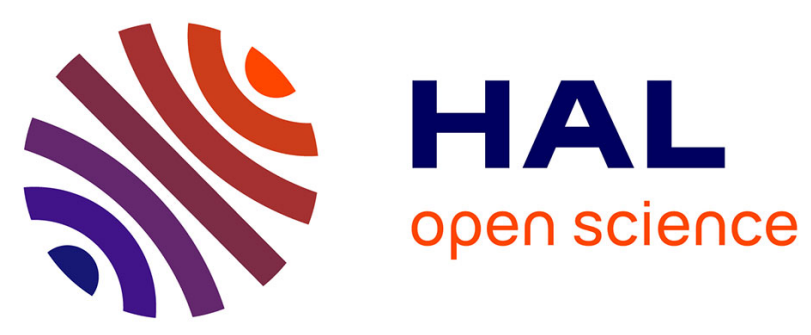

\title{
Present perfects compete
}

Gerhard Schaden

\section{To cite this version:}

Gerhard Schaden. Present perfects compete. Linguistics and Philosophy, 2009, 32 (2), pp.115-141. 10.1007/s10988-009-9056-3 . hal-00535503

\section{HAL Id: hal-00535503 https://hal.science/hal-00535503}

Submitted on 11 Nov 2010

HAL is a multi-disciplinary open access archive for the deposit and dissemination of scientific research documents, whether they are published or not. The documents may come from teaching and research institutions in France or abroad, or from public or private research centers.
L'archive ouverte pluridisciplinaire HAL, est destinée au dépôt et à la diffusion de documents scientifiques de niveau recherche, publiés ou non, émanant des établissements d'enseignement et de recherche français ou étrangers, des laboratoires publics ou privés. 


\title{
Present perfects compete
}

\section{Gerhard Schaden}

\begin{abstract}
This paper proposes a new look at the so-called 'present-perfect puzzle'. I suggest that it is in fact part of a bigger problem, which also involves simple past tenses. I argue that present perfects compete with simple past tenses, and that the distribution of these tenses shows signs of the impact of this competition. The outcome of the competition is argued to be heavily dependent on which of the two tense-forms is the default. A pragmatic theory is proposed which accounts for the reduced distribution of the present perfect in languages like English and (American) Spanish, and the reduced distribution of the simple past tense in languages like French and German.
\end{abstract}

Keywords Tense - Present perfect - Cross-linguistic variation - Competition · Pragmatics · Semantics

\section{Introduction}

The cross-linguistic variation of present perfects has received much attention in recent years. As far as I am aware, all of the scholars involved in the discussion base their claims in one way or another on the influential paper by Portner (2003). This article has been criticised in various aspects. However, the crucial assumption of Portner has remained unchallenged: the behavior of the present perfect in languages

G. Schaden $(\bowtie)$

CNRS, UMR 7110, Laboratoire de linguistique formelle,

30 rue du Château des Rentiers,

75013 Paris, France

e-mail: gerhard.schaden@linguist.jussieu.fr 
like English is to be explained in the core-grammar of the languages involved, that is, either in syntax or semantics. More precisely, according to Portner and his followers, the culprit of the rather eccentric behavior of the present perfect in such languages is - in one way or another-the present tense feature.

The aim of the present paper is threefold: first, I will show that any theory making the assumption of a semantic or syntactic origin of the variation of the perfect tenses will fail, because there is data which contradicts this basic assumption. Second, I will show that the present perfect is not the only tense to vary cross-linguistically: the simple past tense does so, too. Crucially, the simple past tenses vary in a way that is interrelated with the variation of the present perfect tenses. Third, I will propose a new, pragmatic and competition-driven account of the distribution of what I call "one-step past-referring tenses".

Let me define this notion in order to make things clearer: One-step past-referring tenses are tenses which have the effect of locating an eventuality prior to the moment of utterance (thus: past-denoting). It is crucial that they do this directly, and without the intervention of a secondary point of reference between the moment of utterance and the temporal trace of the event (hence, 'one-step past denoting'). ${ }^{1}$ Furthermore, one probably needs to require that the past localisation of the eventuality expressed by the verb concerns the main semantic effect of the sentence, and is not only a 'side effect', like it would be in stative passive forms, for instance. The one-step past-denoting tenses discussed here are the simple past tenses and present perfects of English, Spanish, German and French. ${ }^{2,3}$

\footnotetext{
1 According to the terminology I apply here, one might call a pluperfect a two-step past-referring tense, since there is a point of reference intervening between the moment of utterance and the temporal trace of the eventuality.

${ }^{2}$ For Spanish and French, I will neglect one one-step past-referring temporal form, namely what one might call the 'immediate anteriority periphrases' acabar de (Spanish) and venir de (French), as illustrated in (i). As this form does not seem to have uses outside of reference to events situated immediately before the moment of utterance (or before a contextually fixed point of reference), I do not think that they have much influence on the distribution of present perfects and simple pasts in these languages. Therefore, the basic results of this paper should not be altered by the non-treatment of these forms.
}

(i) a. Pedro acaba de llegar.

P. finishes from arrived.

'Pedro has just arrived.'

b. Pierre vient d' arriver.

P. comes from arrive.

'Pierre has just arrived.'

\footnotetext{
${ }^{3}$ As pointed out by a reviewer, readers familiar with the literature on perfects may be puzzled by the fact that I simply presuppose that perfects are one-step past-referring tenses. Indeed, Extended Now (or perfect-time span) approaches are a priori at odds with that assumption, in that they suppose that a perfects extends the interval of reference into the past. However, there are two points to be made with respect to such theories.

First, such theories suppose that the Now (which is a special case of a moment of reference) is extended unilaterally into the past. Thus, they contain some notion of anteriority (even if it is not proper anteriority). Second, I think that one should clearly distinguish the basic intuitions a theory wants to capture from the formal implementation of those intuitions in that theory. In the case of perfects, the intuitions at stake are the following: there is some relation of anteriority involved, and there is some kind of link involved between the eventuality and the moment of reference. As far as I am aware, this is
} 
The paper is structured as follows: I will first present the problem of the present perfect as it has been stated by Portner (2003) and those adopting his approach. As far as I can see, this is generally agreed upon. Then, I will present some solutions to this problem: the original proposal by Portner, the implementation by Pancheva and Stechow (2004), and the syntactic analysis by Rothstein (2006).

In Sect. 3, I will introduce the idea of competition between present perfects and simple past tenses, and present the data which a (core-)grammar-driven approach of the present perfect variation cannot handle. It will be explained that in a language like English or Spanish, the present perfect is the loser of the competition, whereas in French or German, the simple past tense shows evidence of being blocked in certain contexts.

Finally, Sect. 4 presents the analysis I am advocating. It is based on rather standard assumptions on the semantics of the simple past tense and the present perfect tense, and uses Gricean pragmatics-supplied with a markedness parameter-to explain the respective distributions of these tenses in languages like English vs. languages like French. Some considerations on the grammaticalisation process in which present perfects become more and more past-tense-like conclude the section.

\section{The problem of the present perfect according to Portner (2003)}

It is a well-known fact that present perfects differ cross-linguistically. One of the main points of variation concerns the ability of a present perfect in a given language to combine or not with a localizing temporal expression like yesterday or at five o'clock. In languages like English or Spanish, the present perfect does not combine felicitously with such past-denoting temporal adverbials.

(1) a. *John has arrived yesterday.
b. *Juan ha llegado ayer.
J.

In languages like French or German, such combinations are perfectly felicitous:
a. Jean
est arrivé
hier.
J. is arrived
yesterday.
b. Hans ist gestern
angekommen
H. is yesterday arrived.

Footnote 3 continued

uncontroversial. If both anteriority and the link are encoded directly by temporal means, you get an Extended Now theory; if you separate them, one possibility is proper temporal anteriority with a perfect state taking care of the link. A further indication that the Extended Now interval and the perfect state do the same job is the fact that I do not know of any theory assuming an Extended Now and a perfect state. This seems to be technical overkill.

But on some level, all theories of the perfect need to involve some means of indicating anteriority. Thus I believe that the characterisation of perfects (at least in the four languages at hand) as one-step pastreferring tenses is justified. 
Another difference between these two types of present perfects are the so-called "life-time" effects: dead persons or no longer existing objects are not felicitous in subject-position with a present perfect:
a. \#Einstein has visited Princeton.
b. \#Einstein ha visitado Princeton.
E. has visited P.

According to Portner (2003), (3a-b) are not agrammatical per se; they would require Einstein to be alive in order to be felicitously uttered. In languages like French or German, no such life-time effect obtains:
a visité
Princeton.
E.
has visited
P.
b. Einstein hat Princeton besucht.
E.
has $\mathrm{P}$.
visited.

Various explanations of this pattern have been suggested. Scholars like Klein (1992, 2000) have proposed that there is parametric variation between the PERFECT-features: languages which pattern with English are supposed to have a different configuration of the post-state, which is supposed to be denoted by a perfect. According to Klein, with an English perfect, the subject always outscopes the perfect-operator which introduces a post-state (cf. (5a)), whereas in German, the perfect-operator may or may not outscope the subject of the sentence (i.e., either configuration (5a) or (5b)):
a. Subject POST-Predicate
b. POST-[Subject Predicate]

The top-most position of the sentence would be interpreted with respect to the tensefeature, that is, in the case of a present perfect, with respect to the moment of utterance. (5a) can be paraphrased as follows: at time $t$, the subject is in a post-state of the predicate. (5b) can be paraphrased by: at $t$, we are in a post-state of the subject applied to the predicate. This very nicely explains the life-time effects.

However, as Portner convincingly showed, this cannot be the answer to our problem: in English, the only perfect-form concerned by the restrictions observed so far are the present perfects. No other perfect form, like future or past perfects, as well as perfects embedded under modals, or involved in participial constructions-forms that I will refer to in the rest of the paper as 'non-present perfects'-exhibit any restrictions against localizing past-denoting expressions:

(6) a. Mary had arrived yesterday.

b. Mary will have arrived the day before.

c. Mary might have arrived yesterday.

d. Having arrived yesterday, Mary will be able to accompany us tomorrow.

This is not specific to English: Spanish perfects pattern the same way: 
(7) a. María había llegado ayer.

M. had arrived yesterday.

b. María habrá llegado el día precedente.

M. will have arrived the day before.

c. María debería haber llegado ayer.

M. should have arrived yesterday.

d. Habiendo llegado ayer, María podrá

Having arrived yesterday, M. will be able to

accompañarnos.

accompany us.

As is to be expected, French and German perfects do not show any restrictions in these tenses, either: ${ }^{4}$
a. Marie était arrivée hier.
M. was arrived yesterday.
b. Marie sera arrivée la veille.
M. will be arrived the day before.
c. Marie pourrait être arrivée hier.
M. could be arrived yesterday.
d. Étant arrivée hier, Marie pourra nous accompagner.
Being arrived yesterday, M. will be able us accompany.

(9) a. Maria war gestern angekommen.

M. was yesterday arrived.
b. Maria wird am vorhergehenden Tag ankommen.
M. will at the preceding day arrived.
$\begin{array}{lllll}\text { c. Maria } & \text { könnte } & \text { gestern } & \text { angekommen } & \text { sein. } \\ \text { M. } & \text { could } & \text { yesterday } & \text { arrived } & \text { be. }\end{array}$

The restrictions against localizing temporal expressions are not the only ones to vanish with non-present perfects: as can be shown, there are no life-time effects associated with these tenses either.

(10) In 1942, Hitler attacked Russia. Napoleon had tried before him, but without success.

If there were any life-time effects to be observed with the pluperfect in English, one should expect them to arise at a contextually fixed moment of reference [the Reichenbachian $R$ (cf. Reichenbach 1947/1966)]. In (10), the discourse context fixes $R$ in the year 1942. But at this moment, Napoleon had long been dead. However, (10) remains felicitous. German and French pattern like English in this respect: they do not introduce any restrictions on the pluperfect that were absent with the present perfect.

\footnotetext{
${ }^{4}$ In German, one cannot use the participial construction as freely as in English. The sentence corresponding to (6d) would not be acceptable in German, though for reasons that do not concern the perfect.
} 
The conclusion that has to be drawn from these facts is the following: the English (and Spanish) present perfects have restrictions they do not share with any other construction involving a perfect in the respective language. On the other hand, non-present perfects seem to be rather similar cross-linguistically. Furthermore, the German and French present perfects behave in a way that is consistent with non-present perfects not only in these two languages, but also in English and Spanish.

Therefore, there are good reasons to believe that the French and German present perfects are not odd perfect tempora, lacking the typical current relevance restrictions characteristic for such tenses, as is assumed for instance in the typological literature of what is sometimes called the "Bybee-Dahl school" (cf., for instance Bybee and Dahl 1989). ${ }^{5}$ It appears on the contrary that German or French present perfects are more in line with the general perfect behavior than their English or Spanish equivalents.

Much of the recent literature has tried to explain how the restrictions applying to the present perfect come about, while trying to maintain nevertheless a unified semantics for the PERFECT-feature in languages like English or Spanish.

\subsection{Portner's solution}

One of the key appeals of Portner (2003) is the fact that he manages to give a unified account of the PERFECT-feature in English, by shifting away the problem from the perfect itself to the PRESENT-tense feature. All subsequent work has followed him in this move, although his account of the perfect has been contradicted in several points and has subsequently been heavily modified.

Portner proposes that the impossibility of a sentence like (1) is due to the clash of two different presuppositions: an Extended-Now (XN) presupposition triggered by the present tense, and a non-XN feature triggered by the localizing temporal adverbial.

(11) a. XN presupposition of the Present Tense: A present tense sentence is only usable in context $c$ if the event it describes falls within $c$ 's Extended Now. ${ }^{6}$

b. For any past time adverbial $\alpha$, the use of $\alpha$ in context $c$ presupposes that no event $e$ described by $\alpha$ in $c$ overlaps $c$ 's extended now. ${ }^{7}$

So, when a sentence like (1) occurs, we have two presuppositions which cannot be satisfied at the same time. Therefore, such a sentence is out.

If the idea in itself is tempting, its particular implementation gives us very strange predictions for the reasons of the cross-linguistic variation of the present perfects: as the reason for the incompatibilities observed so far is a presupposition clash, a language like French or German would have to lack at least one of the two presuppositions stipulated by Portner for English.

\footnotetext{
5 As pointed out by a reviewer, there are many approaches that ascribe current relevance at least as a possible reading to the German present perfect (for a recent example, cf. Rothstein 2006, p. 43). Such a claim is not only fully compatible to the claim put forward in this paper, but even to be expected.

${ }^{6}$ Cf. Portner (2003, p. 496).

7 Cf. Ibid.
} 
Secondly, as Nishiyama and Koenig (2004, 102f.) have pointed out, the problem does not seem to be presuppositional. It is a standard assumption that one can attack presuppositional content by means of metalinguistic negation. However, metalinguistic negation cannot make a life-time effect disappear:

*Einstein has not visited Princeton. He is (simply) not alive. ${ }^{8}$

But, even if this particular implementation has not had many followers, Portner's basic idea still remains popular: in some way, it is the PRESENT-feature which causes-possibly in conjunction with other influences-the present perfects to differ cross-linguistically.

\subsection{Other implementations of the 'Present-Tense-As-Culprit' idea}

Pancheva and von Stechow (2004) suppose in their analysis for English and German that these two languages have different present tense features. However, in their analysis, the present tenses of English and German do not differ with respect to their presuppositions, but with respect to the temporal semantics. The intuition behind the formalisations in (13) is that the German present is a non-past, whereas the English would be a 'real' present tense (cf. Giorgi and Pianesi 1997).

$$
\begin{aligned}
& \text { a. } \quad \text { ppresent } \rrbracket=\lambda p \cdot \lambda i[i=n \wedge p(i)][\text { English] } \\
& \text { b. } \quad \text { [present } \rrbracket=\lambda p \cdot \lambda i[n \preceq i \wedge p(i)][\text { German] } \\
& \text { where } t \preceq t^{\prime} \text { iff there is no } t^{\prime \prime} \subset t^{\prime} \text { such that } t^{\prime \prime} \prec t .
\end{aligned}
$$

What one should generally expect according to such a proposal is that languages with similar present tenses have similar present perfects. This, however, is not the case, as has been argued by Rothstein (2006). While the Swedish present tense patterns systematically with the German present tense against the English present, the Swedish present perfect behaves like the English present perfect, e.g. in not allowing for a past adverbial to apply to the present perfect:

$$
\begin{aligned}
& \text { a. *Sigurd har kommit igår }{ }^{9} \text { [Swedish] } \\
& \text { S. has come yesterday. } \\
& \text { b. *Sigurd has arrived yesterday. } \\
& \text { c. Sigurd ist gestern gekommen. [German] } \\
& \text { S. is yesterday come. }
\end{aligned}
$$

Based on the Swedish data, Rothstein concludes that the behavior of the present tense in a language is not correlated with the behavior of the present perfect in the same language.

\footnotetext{
${ }^{8}$ Compare (12) with the (metalinguistic) negation of a prototypical presupposition: The king of France is not bald. There simply is no king of France.

9 Example taken from Rothstein (2006, p. 74).
} 
Rothstein's own proposal is very much in the spirit of Portner, and follows a lead by Musan (2002): according to this idea, in languages like English and Swedish, the present feature is able to restrict the choice of the localizing temporal adverbial, whereas in languages like German, this is not the case. He assumes a basically syntactic mechanism, where something like a non-past feature of the PRESENT enters in conflict with the past-denotation of the temporal adverbial. Basing his proposal on syntactic c-command, Rothstein predicts that in languages with restricted present perfects, the temporal adverbial is c-commanded by the perfect auxiliary, and therefore, the auxiliary is able to restrict the choice of the temporal adverbial. In languages with an unrestricted present perfect tense, the perfect auxiliary does not c-command the temporal auxiliary, and is not able to interfere on the selection of a temporal adverbial. However, this proposal, designed for the Germanic languages, cannot be applied to French.

Rothstein's test involves clefting or topicalisation of the perfect auxiliary conjointly with the participle. In the Germanic languages, this seems to work: in languages with a restricted present perfect, the perfect auxiliary cannot be clefted or topicalised conjointly, whereas in German, this is possible:

$$
\begin{aligned}
& \text { a. ... weil er ein Ufo gesehen haben muss. } \\
& \ldots \text { because he a ufo seen have must. } \\
& \text { '... because he must have seen a ufo.' }
\end{aligned}
$$

b. [gesehen haben] muss er ein Ufo.

Seen have must he a ufo.

Subordinate clauses like (15a) are considered to represent the base position of constituents in German, which is SOV. As can be seen in (15b), the participle gesehen can be displaced along with the auxiliary haben, which means that they form a constituent. ${ }^{10}$ In English, such a move is impossible: ${ }^{11}$
a. *Have hidden money in the mattress and jewels in the sewing basket, she may.
b. *What she may have done is have hidden money in the mattress and jewels in the sewing basket.

However, French behaves like English, and not like German with respect to this constituency-test:

\footnotetext{
${ }^{10}$ It is important to notice that [gesehen haben muss] has not moved as one block, and that it does not form a constituent. German is considered to be a SOV-V2 language (cf. Müller 2005: for apparent exceptions to this pattern). In a main clause, like in (15b), the finite verb must end up in second position. Such finite-verb movement is completely independent of topicalisation, which applies here subsequently and moves a constituent into the first position.

${ }^{11}$ Examples in (16) from Rothstein (2006, p. 78).
} 

a. *Avoir vu
un
ovni, elle le
peut.
Have seen
a ufo, she
it can.
b. *Ce qu'elle peut avoir fait, c'est avoir vu un ovni.
That what she can have done, that is have seen a ufo.

Therefore, this syntactic analysis is also not able to provide a general theory for the reason of the cross-linguistic variation of the present perfect tenses. As far as I am aware, there is currently no theory available that establishes a convincing correlation between the cross-linguistic variation of present perfects and another grammatical phenomenon. ${ }^{12}$

\section{Arguments for competition between one-step past-referring tenses}

The solutions for the cross-linguistic variation we have reviewed so far share many features and assumptions. They all assume that the configuration of the PERFECTfeature is not involved in the cross-linguistic variation of the present perfect, nor in the variation of the perfect tenses within a single language like English. This is probably one of the reasons why this type of analysis has become as popular as it has in the first place: it becomes possible to suppose a single PERFECT-feature for a language like English, and maybe even one single PERFECT-feature throughout at least the majority of Romance and Germanic languages. While the assumption of one uniform PERFECT is certainly highly desirable from a theoretical point of view, it does not seem that clear to me that the semantics of the PERFECT should be entirely evacuated from the question. Indeed, I will propose that it plays a key role in the cross-linguistic variation of the present perfects.

More importantly, all approaches presented in Sect. 2 assume that what is sometimes called the 'present perfect puzzle' is a problem in its own right. I strongly oppose this assumption, and propose that it is a part of a bigger puzzle, which also involves the simple past tenses. The hypothesis I will defend here is that present perfects have to compete against simple past tenses, and that this fact influences their distribution.

\footnotetext{
12 Rothstein (2006) discusses whether the fact of having two perfect auxiliaries rather than one might be correlated with the behaviour of the present perfect. English and Spanish have only maintained have as an auxiliary, whereas French and German use both have and be as perfect auxiliaries. So, does a language with two perfect auxiliaries have a rather unrestricted present perfect? Rothstein dismisses the idea, because Danish, while having both have and be as auxiliaries, patterns with English rather than with German [examples in (i) taken from Rothstein (2006, p. 76)]:
}

(i) a. *Han er kommet igår.

$\mathrm{He}$ is come yesterday.

b. *Han har arbejdet igår.

He has worked yesterday. 
As a first step, I will show that sentences of type (1), even if they are marginal, do exist in languages like English and Spanish.

Then, I will turn to evidence that there are restrictions to be observed on the French and German simple past which do not exist in English or Spanish.

\subsection{How agrammatical is it?}

One crucial ingredient of all theories presented in Sect. 2 is that they all assume that the cause of the variation is rooted somewhere in the semantics or the syntax of the language under consideration. This is a very strong commitment: the reason for the variation is situated in the core-grammar of the language. Therefore, one should expect that the constraints should be inviolable, and that, for instance, it is truly agrammatical in English or Spanish to have a sentence with a present perfect and a localizing temporal adverbial. ${ }^{13}$ Now, while I do not doubt that this incompatibility is a very strong tendency in those languages, I do not think that it is more than a very strong tendency. Crucially, it is not the case that sentences like (1) are completely absent from corpora and from the literature on perfect tenses. For English, at least the following are attested in trustworthy sources: ${ }^{14}$

(18) a. We have received information on F.S. from you on the $22^{\text {nd }}$ of September last. ${ }^{15}$

b. Thank you, the point which Mr has made yesterday, I think will continue to make $[$ sic $] .{ }^{16}$

c. In the event my Lord, erm, that er your Lordship felt that further guidance was required, there are the two routes that I've indicated to your Lordship briefly yesterday, [...]

In Spanish corpora, one also finds attestations of such constructions:

Don Fulano de Tal y Tal ha muerto $\begin{aligned} & \text { ayer, } \\ & \text { a a las }\end{aligned}$
D. F. d. T. y T. has died
seis de la tarde. ${ }^{17}$
six of the afternoon.
'Don Fulano de Tal y Tal has died
o'clock in the afternoon.'

\footnotetext{
${ }^{13}$ Hence the '*' I put in front of the examples like (1).

14 A Google-query on "has died yesterday" or "ha muerto ayer" brings a great quantity of hits. However, one could still explain them as the result of the production of non-natives.

15 Example taken from Maurice (1935), cited from McCoard (1978, p. 129).

16 Examples (18b-c) found in the British National Corpus, http://www.natcorp.ox.ac.uk [11-09-2007]. Query: "has_yesterday".

17 L. Rosales, Cervantes y la libertad. REAL ACADEMIA ESPAÑOLA: Banco de datos (CORDE) [online]. Corpus diacrónico del español. http://www.rae.es [11-09-2007].
} 
Were these constructions really agrammatical in the strict sense of the word, one should not find them at all in such corpora. But they are attested. ${ }^{18}$ At the same time, they seem to be too marginal to indicate a grammaticalisation process shifting English or Spanish present perfects closer to French or German perfects. On an intuitive level, what these sentences have in common is that they clearly express an eventuality which is currently relevant, but where the exact localisation of the event causing the perfect state has its importance. In such contexts, present perfects with a localizing temporal adverbial seem to be more acceptable, and can be produced even in languages like English or Spanish.

However, the examples in (18) and (19) would be quite normal if what was at stake was not agrammaticality, but competition, leading to partial blocking. If for some reason the 'normal' form to take in such contexts were the simple past, one would expect to find overwhelmingly the simple past. However, one would not expect to find them always: in less normal contexts, the less normal form might appear.

I think that nobody would deny that there are at least some contexts in which one can choose more or less freely between a simple past tense and a present perfect tense. Yet, in other contexts, one has to choose one form rather than the other. For instance, in English, for all the examples marked as agrammatical in examples (1)-(4), where the tense was a present perfect, one could have used felicitously the simple past, as is shown in (20a) and (21a). In German and (with some restrictions,) French, one has the (free?) choice in all these contexts which form to use. The present perfect in examples (2) and (4) was grammatical, but in the same grammatical context, one could have also used a simple past tense, as is shown in (20cd) and (21cd).

\begin{tabular}{lll|ll} 
a. Mary & arrived yesterday & at five o'clock. \\
b. María & llegó & ayer & a las cinco. \\
M. & arrived yesterday & at the five.
\end{tabular}

(Spanish)

${ }^{18}$ One way out for a tenant of a semantic or syntactic theory of the present perfect variation would be to say that the attested examples come from particular sociolects or dialects (probably substandard, and therefore not well represented in corpora), and that they show a different grammar, which is not identical to the standard English and Spanish grammars. I agree that this is an empirical question which needs to be investigated more thoroughly. Notice, however, that all the sources cited here come from rather formal situations of speaking or writing.

As pointed out by Brenda Laca (p.c.), formal situations may however provide another source of speaker errors with respect to the distribution of present perfects with past-denoting adverbials, namely hyper-correction. Speakers of varieties with very marginal present perfects, as is the case for instance in Argentinean Spanish (cf. Burgos 2004), may over-extend the use of these forms in formal speechsituations - if the speakers are conscious of the fact that the present perfect is used more frequently in the more prestigious varieties.

But though there may be a little hope left to treat such examples within a core-grammatical theory focalizing exclusively on present perfects, such a theory would have nothing to say about the respective distribution of the simple past tense. Therefore, from a theoretical point of view, I think that the approach put forward here is able to provide more insight than the competing approaches, and should be pursued. 


\begin{tabular}{|c|c|c|c|c|c|c|}
\hline Marie & arriva & \#hier ${ }^{19}$ & & cinq & heures. & (French) \\
\hline & arrived & yesterday & & 2 & o'clock. & \\
\hline Mari & kam & gestern & um & fünf & an. & (German) \\
\hline & arrived & yesterday & & ine & on. & \\
\hline
\end{tabular}

$\begin{array}{llll}\text { a. Einstein } & \text { visited } & \text { Princeton. } \\ \text { b. } & \text { Einstein } & \text { visitó } & \text { Princeton. } \\ \text { E. } & \text { visited } & \text { P. } \\ \text { c. } & \text { Einstein } & \text { visita } & \text { Princeton. } \\ & \text { E. } & \text { visited } & \text { P. } \\ \text { d. } & \text { Einstein } & \text { besuchte } & \text { Princeton. } \\ \text { E. } & \text { visited } & \text { P. }\end{array}$

Now, if the assumption is correct that the restrictions on the present perfects in languages like English and Spanish are the result of the competition of this tenseform with the simple past, one would expect there also to be restrictions on the use of the simple past in languages like French and German. It would be rather odd to have competition going on with no loser on either side.

Here, we touch the main claim of the paper: the cross-linguistic variation of the present perfect is not an isolated phenomenon; it has to be seen in connection with the cross-linguistic variation of other tenses that could, in principle, be used in the same contexts. The more restricted a present perfect is, the less restricted the simple past tense will be, and vice-versa. There is no obvious way of deriving this claim without having recourse to competition, and some way of accounting for competition. As far as I can see, nothing guarantees for instance that the meaning of a simple past tense will simply diminish as the (hard-coded, core-semantical) meaning of the present perfect advances. However, as I will argue, at least in the languages I am considering here, the simple past tenses and the present perfect tenses seem to have connected distributions: the more one sees of one form, the less one sees of the other.

In the next section, I will show that there is indeed evidence for a more restricted use of the simple past tense in French and German. More precisely, the kind of restriction that can be observed is exactly the one to be expected if it was due to the interference of a 'stronger' present perfect tense.

\subsection{French and German simple pasts as victims of competition}

Kratzer (1998) noted that in some contexts, the German simple past cannot be used where the English simple past is felicitous. Suppose a context for (22) where the speaker and the addressee are standing together in front of the church they are talking about:

\footnotetext{
19 In French, the passé simple is not felicitous with localizing adverbials having a link to the moment of utterance, like yesterday.
} 

a. \#Wer
baute diese
Kirche? Borromini
baute
diese Kirche. who
built this
church?
B.
built this
church.
b. Who built this
church?
Borromini
built this
church.

(22a) clearly would be infelicitous in such a situation. According to Kratzer, it might at best be produced as a hypercorrect utterance of a Southern German speaker, who has not mastered the simple past tense. ${ }^{20}(22 \mathrm{~b})$, however, would be perfectly normal in such a situation.

Kratzer's observation has not drawn much attention, and crucially, it has not been noted that this is not an isolated phenomenon of German and English simple past tenses. The very same opposition can be observed between French and Spanish:

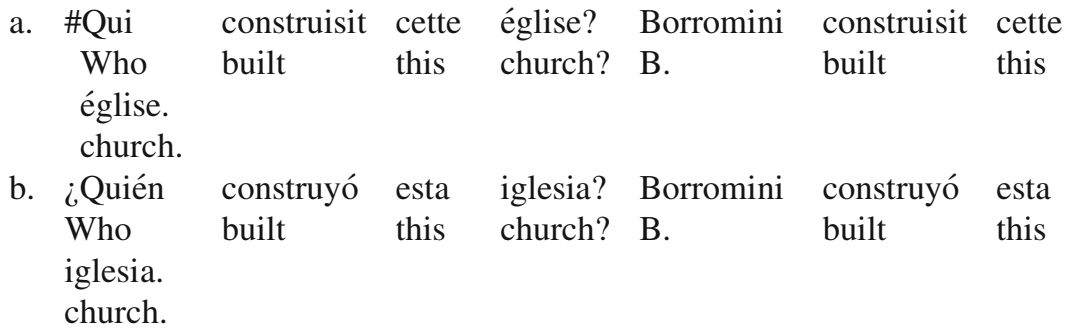

(23a) is as odd as (22a), for the very same reasons. (23b) seems to be the normal way of saying things.

One of the reasons for the lack of impact of Kratzer's discovery might be the fact that her context is rather picturesque, and does not provide an easy test for further investigation. This may also have obscured the link between (22a) and some much older observations by Benveniste (1966/1974) and Weinrich (1986, 1993): somehow, the simple pasts in German and French impose a textual level which sets the described events as being separate from the speaker and the addressee (Benveniste's récit, and Weinrich's erzählte Welt-'narrated world'), whereas the textual level associated with the present perfect is closer to the discourse-participants (discours for Benveniste, besprochene Welt $\approx$ 'talked-about' world for Weinrich).

I will try to provide elements here that can serve as a base for an operational test for this behavior of simple past tenses. Furthermore, I will try to give a formal account of the simple past's behavior which accounts for the observations made by Benveniste and Weinrich.

The contexts in German and French where one cannot use the simple past are contexts where-as a first approximation-some "current relevance" of the event under discussion is required. ${ }^{21}$ Note that these are the core-contexts of the use of a present perfect, insofar as they are identified with the meaning of the perfect under

\footnotetext{
${ }^{20}$ The Southern German dialects do not use the simple past tense any more, except for some modals and the auxiliaries have and be (cf. Lindgren 1957).

21 The notion of "current relevance" has been heavily criticised in the literature for being too vague to serve as a ground for a semantic analysis (cf., e.g. Klein 1992). I do agree with this criticism. However, here, it provides me with a useful shorthand to refer to phenomena often discussed in the literature about perfects, in principle without committing to any particular technical implementation.
} 
many accounts (cf. Dahl 1985). Both English and German perfects have been repeatedly described as involving some notion of current relevance.

As has been pointed out by a reviewer, it is difficult to come up with operational tests for current relevance that eliminate entirely the imagination of the hearer. I think, however, that there are elements which allow to reduce the margin that has to be left for imagination. First of all, what seems to be wrong with (22a) in German is that there exists at the moment of utterance an object resulting from the event expressed in the perfect. It is infelicitous in German to use a simple past while pointing at such an object. Analogous examples can easily be constructed: imagine the sentences in (24) in a context where the speaker points to the picture painted by his/her daughter.

(24) a. My daughter painted this.

b. \#Meine Tochter malte das. My daughter painted this.

If (24b) can be interpreted, it is in my mind only as "the thing represented in this picture has been painted at some time in the past by my daughter", but not as "this is a picture that my daughter painted". In German, in order to allow for that latter interpretation, one needs to use the present perfect.

Another way of at least strongly suggesting current relevance is the following: imagine a context where some important consequence of the event is required, and where the utterance is preceded by an exclamation like Oh my god!, Yesss! or Look! ${ }^{22}$

In such contexts, French or German simple past tenses are completely impossible, whereas English and Spanish simple past tenses are fine:

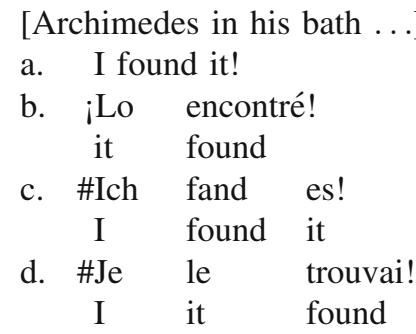

(26) [Kasparov to Deep Blue ...]

a. I won!

b. ¡Gané!

won

c. \#Ich gewann!

I won

d. \#Je gagnai!

I won

Had Archimedes spoken English or Spanish, he would have been able to shout his eureka in the simple past tense. Had he spoken contemporary French or German,

22 As a reviewer of the paper has pointed out, such exclamations on their own cannot guarantee current relevance, since the following sentence turns out to be acceptable:

(i) Oh mein Gott! Goethe schrieb Die Räuber.

O my god! Goethe wrote The Robbers.

Die Räuber, an 18th century drama and masterpiece of the Sturm und Drang, made its author Friedrich Schiller famous. (At least as far as I know,) Johann Wolfgang von Goethe was not involved in its elaboration. It is difficult to imagine how (i) could nowadays have current relevance in a reasonable sense. In (i), $O$ my God! seems to express surprise, rather than current relevance. 
it would have been entirely impossible for him to use the simple past: it is extremely odd to convey something like "I am in a post-state of a finding-event, and this finding-event caused my current knowledge of the matter" by using a simple past. ${ }^{23}$

Similarly, if in the joy of victory Kasparov were to claim his superiority to his adversary, he could use the simple past tense in English or Spanish, but not in German. One can once more paraphrase the meaning of this sentence by using the idea of a post-state: "I am in a post-state of a winning-event, I am a winner (and you are crushed)."

For the examples in (25) and (26), in French and German one has to use a present perfect tense.

Finally, one may resort to to prototypical current relevance contexts, like the one provided by the Gospel of St. Mark, 15, 34: And at the ninth hour Jesus cried with a loud voice, saying, Eloi, Eloi, lama sabachthani? which is, being interpreted, [... $]^{24}$

a. My God, my God, why did you forsake me?

b. Dios mío, Dios mío, ¿por qué me desamparaste?

God mine, god mine, why me forsake?

c. \#Mein Gott, mein Gott, warum verließest Du

My god, my god, why forsake You

mich?

me?

d. \#Mon Dieu, mon Dieu, pourquoi m' abandonnas- tu?

My god, my god, why me forsake you?

In both English and Spanish, one can have a present perfect in such a context; this is completely impossible in German or French. The rationale behind this is the following: in (27), what is at stake is not only a past event of forsaking, but also (and probably principally) a present state of being alone, which is the consequence of the past event.

The general idea emerging from these examples is the following: even though the present perfect in languages like English or Spanish has sometimes been characterised as being a better example of a perfect because of its dominant currentrelevance character, it is not the only way to express current relevance in these languages. In French or German, however, in order to bring across something like "current-relevance", one has no other choice than to use the present perfect.

\footnotetext{
23 This has not always been the case: in Middle-High German (11th-14th century AD), there was a class of so-called Präteritopräsentien, that is, semantically present tense verbs which morphologically were simple pasts. Among these verbs was wissen ('to know'), which morphologically was a simple past form of a root meaning to see.

24 The standard translations of the Bible in all four languages under discussion use the present perfect in this context (the site http://www.biblegateway.com provides an easy way of checking this). However, on religious websites in English and Spanish, one finds the version with the simple past.
} 
This can be depicted in the following diagrams:

a. English, Spanish:

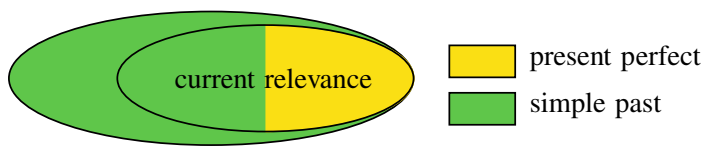

b. French, German:

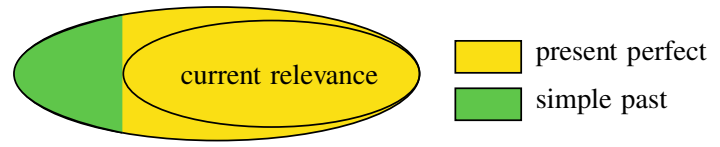

The central ellipsis represents the current relevance readings one could want to express: in English and Spanish, one can-but does not have to-use the present perfect in order to do so; in French and German, one has to use the present perfect if the event under discussion is to belong to the currently relevant items.

The key generalisation I would like to establish is the following: in languages like English or Spanish, you are almost always able to use to simple past tense, and sometimes, you have to use it. In languages like French or German, you are almost always able to use the present perfect, and sometimes, you have to use it.

This distribution can be seen as the result of the opposition between a default form and a marked form. The marked member is either the present perfect (like in English or Spanish) or the simple past (like in French or German).

\section{The analysis}

The analysis put forward here supposes that the cross-linguistic variation of present perfect tenses is a sub-problem of a bigger problem, namely the cross-linguistic variation of one-step past-referring tenses. This problem involves at least the crosslinguistic variation of simple past tenses in addition to the variation of present perfects.

\subsection{Semantic underpinnings}

In order to be as specific as possible concerning the semantics underlying the pragmatic reasoning, I present in (29a) the compositional semantics I assume for the past tense feature, and in (29b) the composition of the present tense feature with the perfect feature.

a. $\quad \llbracket$ past $\rrbracket=\lambda p \exists i[i \prec n \wedge p(i)]$ where $n$ is the moment of utterance, $i$ an interval, and $p$ a variable over propositions. ' $\prec$ ' denotes a relation of strict precedence. 
b. $\quad$ present $\circ$ perfect $\rrbracket=\lambda p \exists i, i^{\prime}, s\left[n \subseteq i \wedge i^{\prime} \prec i \wedge Q(s) \wedge i \subseteq \tau(s) \wedge p\left(i^{\prime}\right)\right]^{25}$ where $n$ is the moment of utterance, $Q$ a free variable, and $s$ is the perfect state. $\tau(s)$ denotes the running time of the state.

The representation of the PAST-feature is straightforward: it localises an interval prior to the moment of assertion.

Let us now go through the present o perfect. The first condition ' $n \subseteq i$ ' comes from the present feature, and says that the moment of utterance is included in (or equal to) some other interval, which I take to be the moment of perspective $P$, as introduced in Kamp and Reyle (1993). The temporal relation of inclusion I adopt is a standard semantics for the PRESENT in neo-Reichenbachian analyses. The rest is the contribution of the PERFECT feature. We start with the temporal contribution of the perfect: it is a relation of strict anteriority of the interval of assertion-which corresponds to the topic time of Klein (1992), that is, the interval the speaker makes a claim for-with respect to the interval introduced by the present tense. ${ }^{26}$ As the moment of utterance is included in that latter interval, the interval of assertion will be also prior to the moment of utterance. The assumption of the perfect denoting a relation of strict anteriority is the standard assumption in DRT (cf., e.g., Kamp and Reyle 1993; de Swart 1998), although recent years have seen a regain of interest in Extended-Now theories of the perfect (cf. Alexiadou et al. 2003). The next condition we see, ' $Q(s)$ ', means that we have a free predicate variable over the perfect state $s$. This variable has to be resolved in context by pragmatic reasoning, as has been argued by Nishiyama and Koenig (2004). The next condition ' $i \subseteq \tau(s)$ ' orders the running time of the perfect state around the interval introduced by the present tense, and therefore, indirectly also around the moment of utterance (because $n \subseteq i$ ).

The rationale of the perfect state is that it captures the current-relevance meaning associated with the perfect. Through the pragmatic reasoning needed to resolve the anaphoric nature of the perfect state's predicate variable, one can capture the wide range of possibilities that can be conveyed by the use of a perfect. Consider a sentence like the following:

Brutus has bought a dagger.

(30) might have current relevance in several different contexts, and induce different kinds of current relevance. Suppose, for instance, that Caesar knows that someone is plotting against his life, but that he does not know who. In this context, by uttering

\footnotetext{
25 The function-composition has the following two ingredients:

(i) $\quad$ a. $\llbracket$ present $\rrbracket=\lambda p \exists i[n \subseteq i \wedge p(i)]$

b. 【perfect $=\lambda p \lambda i \exists i^{\prime}, s\left[i^{\prime} \prec i \wedge Q(s) \wedge i \subseteq \tau(s) \wedge p\left(i^{\prime}\right)\right]$

where $Q$ is a free (predicate) variable, and $s$ is the perfect state, $\tau(s)$ denotes the running time of the state.

26 Readers familiar with the work of Wolfgang Klein will note that the assumption of a moment of perspective between the moment of utterance and the interval of assertion is a major departure from Klein's original work. However, as I have argued in Schaden (2007), the criteria developed by Klein actually require the introduction of a supplementary interval for perfects.
} 
(30), one would invite Caesar to infer that $Q$ could be Brutus is the plotter. Now imagine that someone asks himself if he can go out at night in Rome without being attacked. Suppose furthermore that it is common knowledge that Brutus often goes out at night. Then, the utterance of (30) could induce one to infer a perfect state like It is insecure to go out. Such states have been argued in Nishiyama and Koenig (2004) to be sufficiently permissive to allow for those inferences, while being sufficiently restrictive to exclude improbable states. ${ }^{27}$

So, by resorting to a perfect state, we do not need an Extended-Now interval stretching into the past, which is supposed to take care of the same thing. Note that something very similar to a perfect state (although presuppositional in nature) has been argued for by Portner (2003, p. 499).

Let us consider now why it is that the simple past tense and the present perfect can enter into competition. Like the past tense, the composition of the present with the perfect situates an interval before the moment of utterance. However, the present perfect has got a much "heavier" semantics than the simple past: it introduces a state, and a free variable concerning the property of the state. ${ }^{28}$

The semantics of the tense-aspect system presented here will now form the input for a pragmatic reasoning process. My proposal can be summed up as follows: the restrictions observed on the present perfect in languages like English or Spanish and the restrictions on the simple past tense in languages like French and German are the consequences of a basically pragmatic reasoning based on the presence or absence of a perfect state.

I will specify in the next section how this works precisely.

\subsection{The pragmatics}

If a speaker of any of the languages discussed wants to localise an interval of assertion at some moment prior to the moment of assertion, (s)he has the choice of two one-step past-referring tenses which accomplish this task: the present perfect tense and the simple past tense. However, these tenses do not have exactly the same semantics. Crucially, one of these two forms involves the introduction of a perfect state, whereas the other one does not.

\footnotetext{
${ }^{27}$ One main issue is to eliminate arbitrary states that are temporally posterior to the event in the sentence, but otherwise completely unconnected to it. Suppose that into the interval between Brutus' buying a dagger and the time of the utterance of (30) falls the death of a moth in Yucatán. These two events are about as unrelated as it can get. In approaches that do not impose any constraints on the nature of the state $s$, The moth is dead should be a possible perfect state. However, intuitively, such a state should not qualify as a perfect state for (30).

${ }^{28}$ Kjell Johan Sæbø (p.c.) brought up the question of whether the analysis I am proposing really needs such a rich semantics for the perfect, or if a lighter version would do. It is possible that the pragmatic analysis I will develop could be implemented with other semantics of the perfect. However, I think that this is the right one. As it stands, my analysis requires minimally the assumption that a perfect introduces a perfect state, additionally to the temporal anteriority component (which would correspond to the semantics de Swart (1998) proposed for the PERFECT-feature).

More generally, I think that the basic line of thought- that is, pragmatics enriching semantic meaning differently according to different markedness-parameters - could also be brought to work with at least some Extended Now analyses (as far as I see, the one developed by Rathert (2001) would support such a type of pragmatic reasoning).
} 
The restriction-effects working against the use of a present perfect cannot, however, be a direct consequence of the presence or absence of a perfect state. Indeed, they do not arise with pluperfects or any other non-present perfect. Therefore, they must somehow be related to the situation of competition between the simple past and the present perfect, that is, a situation where a speaker has a choice of using a form with a perfect state, and another form without a perfect state. This is not the case for any non-present perfect, and I illustrate this in (31) for the pluperfect: we do not have at our disposal a form that has the same temporal configuration as the pluperfect, but that lacks a perfect state (a form which would correspond to the formula in (31b)):

$$
\begin{array}{lll}
\text { a. } & \text { past } \circ \text { perfect } \rrbracket=\lambda p \exists i, i^{\prime}, s\left[i \prec n \wedge i^{\prime} \prec i \wedge Q(s) \wedge i \subseteq \tau(s) \wedge p\left(i^{\prime}\right)\right] \\
\text { b. } \llbracket \text { past } \circ ? \rrbracket=\lambda p \exists i, i^{\prime}, s\left[i \prec n \wedge i^{\prime} \prec i \wedge p\left(i^{\prime}\right)\right]
\end{array}
$$

The pragmatic analysis outlined in this section will capitalise on the distinction between a default form and a marked form. I will basically assume that the use of the marked form needs to be justified and will trigger a pragmatic reasoning process, whereas the use of the default form does not have to be justified and will therefore not trigger any additional inferences.

I would like to note at this point that it is not possible to simply derive the markedness from some intrinsic properties of the present perfect and the simple past, as one could do in a framework of bidirectional Optimality Theory. According to standard assumptions of morphological and semantic markedness, the present perfect should always be the marked form, as it is morphologically more complex (two words-auxiliary plus participle-instead of just one). From the semantic point of view, the notion of markedness is more difficult to implement; however, based on a discussion by Levinson (2000), I will assume that the semantically marked form is compatible with fewer possible situations than the unmarked form. The cardinality of two sets of possible worlds is difficult to evaluate per se; however, it boils down to entailment in our case. The present perfect asymmetrically entails the simple past in the semantics presented in (29). Therefore, the simple past is compatible with more possible worlds, and thus the semantically unmarked form.

I have assumed that the semantics of present perfects are identical for the languages investigated here, and that these languages also attribute one and the same semantics to their simple past tense. They all use a synthetic form for the simple past, and a compound form for the present perfect (or perfects more generally). I therefore need to assume that the markedness of one of the two forms cannot be simply derived from morphological or semantic markedness, because otherwise, the present perfect should always turn out to be the marked form. However, I will argue that in German and French, it is the unmarked form.

The two basic configurations under this hypothesis are illustrated in the diagrams in (32): 
a. English, Spanish:

\begin{tabular}{cc}
\hline Default form: & Marked form: \\
\hline Simple past tense & Present perfect \\
$\Downarrow$ & $\Downarrow$ \\
no pragmatic effect & triggers pragmatic reasoning
\end{tabular}

b. French, German:

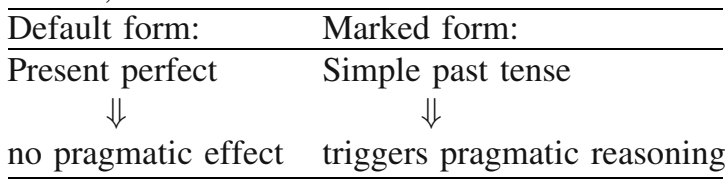

The pragmatic effect needs to be based on the presence or absence of a perfect state. My hypothesis is that it can be interpreted in two ways, depending on whether it is the default form or not. In the case of the use of the unmarked, default form, the presence or absence of the perfect state will not be interpreted.

Let us consider first the case of a language like English or Spanish. If a speaker wants to locate an event (or the interval of assertion) prior to the moment of utterance, without any intervening moment of reference, (s)he can either use the default simple past or the marked present perfect. Now, if the marked present perfect is used, even if the speaker does not have to use the marked form, the listener will infer that there is a reason to introduce a perfect state. This reason can only be the presence of a repercussion of the event in the past for the moment of utterance. The hearer will thus infer the existence of such repercussions, which will provoke an effect of "current relevance". However, the use of a simple past tense will not exclude the existence of an immediate repercussion of the event for the moment of utterance; it merely does not invite the addressee to directly infer something like "current relevance" from the choice of the tense-form. Contextual clues might prove sufficient to impose a current relevance reading of a sentence in the simple past.

The situation is different in languages like French or German, where the present perfect tense is the default form. Here, the default comes with a perfect state, so its presence will not be interpreted any further. ${ }^{29}$ However, if the speaker chooses to refer to an event situated prior to the moment of utterance with a simple past tense, the addressee will try to interpret the absence of a perfect state. The event in this case will be taken to lack any specific link with the moment of utterance, and consequently, it will be taken as a denial of current relevance for the event under discussion.

Thus, we are able to explain how the general pattern of distribution between the simple past tense and the present perfect comes about in two types of languages, capturing the ideas of Benveniste and Weinrich. Similarly, the explanation makes it clear why the restrictions of the present perfect in a language like English do not carry over to the other forms of the perfect: with only one form, that form is by

\footnotetext{
29 Notice that this is also what happens with English and Spanish non-present perfects, where there is no form lacking a perfect state competing with the perfect.
} 
definition the default, and even if it brings along a perfect state, this will have no impact on the interpretation.

This also provides a typological prediction: according to my pragmatic, competition-based account of the variation of the present perfects and the simple past tenses, in a language with only one one-step past-referring tense, ${ }^{30}$ there should not be any restriction on that tense (neither life-time effects, restrictions on its combination with temporal adverbials nor a 'non-current relevance restriction'). However, if these restriction-effects are caused by semantic or syntactic mechanisms, the only one-step past-referring tense of a language might be restricted in one or the other way.

\subsection{Explaining the "incompatibilities"}

In this section, I will try to explain one by one the origin of what I have been referring to so far as "incompatibilities". According to the line of thought developed in this paper, these are rather strong dispreferences, which should be pragmatically motivated. In the following, I will show that they do indeed follow from Gricean conversational maxims (cf. Grice 1975), if one assumes that one of the two tenses is marked. I will start with the "incompatibility" of the simple past with currentrelevance readings, and then discuss the incompatibilities of the present perfect, namely the incompatibility with localizing temporal adverbials, and finally, lifetime effects.

\subsubsection{Simple pasts and current relevance}

The problem, repeated again here, is to know why one cannot use the simple past for contexts in which the event under discussion has important consequences at the moment of utterance, like in the example in (33):

\#O Gott! Ich überfuhr meine Katze mit dem Auto!
O God! I over-drove my cat with the car!
'O God! I killed my cat by running over it with the car!'

This is an incompatibility that arises in languages where the present perfect is the default form. The addressee expects therefore that the speaker must have some motivation in order to omit the assertion of a perfect state in a situation where (s)he did not have to. For a sentence like (33), the perfect state would express a strong presence of repercussions. Given the possibility of the use of an alternative form which would simply provide the perfect state, the utterance in (33) is not sufficiently informative, and would therefore be contrary to the first maxim of quantity ("Make your contribution as informative as is required for the current purposes of the exchange"). Since the speaker knows that the addressee would infer a lack of connection between the event and the moment of reference from the use of a simple

\footnotetext{
30 Such a language would be Latin, where the perfectum (the morphological ancestor of the Spanish and French simple past tenses) is the only perfective tense which is one-step past-referring. As far as I have seen, there are no restrictions of the type discussed on the Latin perfectum.
} 
past tense in this situation, which is contrary to the aim of the speaker, the speaker must choose a present perfect in this context.

Given a speaker that respects Gricean maxims and who is cooperative, I do not see any reason or any context which would make a simple past tense felicitous or even acceptable. ${ }^{31}$ Therefore, one would not expect there to be exceptions to the use of the present perfect when a current relevance interpretation is intended by the speaker.

\subsubsection{Present perfects and localizing temporal expressions}

We have already seen that this is a domain where there are attested examples in which a present perfect can appear with a localizing temporal expression, even in languages where the default form would be the simple past tense (e.g. the example (18a), repeated here as (34)):

(34) We have received information on F.S. from you on the $22^{\text {nd }}$ of September last.

The dispreference for such constructions appears only in languages where the simple past tense is the default one-step past-referring tense.

The preference for the simple past in such contexts can be explained as follows: the simple past as such does not exclude the event from having even strong repercussions at the moment of utterance. However, if the localisation of the event is important—which seems to be the case for sentences like (34), because of the indication of the time-, why should the speaker bother to introduce an extra perfect state when he does not have to? This would be a violation of the second maxim of quantity ("Do not make your contribution more informative than is required").

However, in such a context, the maxim can be flouted in case not only the localisation of the event is important, but simultaneously the consequences of the event for the moment of utterance. And indeed, the examples where we had a present perfect with a localizing temporal expression seem all to be of that kind.

\subsubsection{Life-time effects with the present perfect}

Among the restrictions discussed in this paper, life-time effects appear to be the most likely to undergo contextual manipulation. It has often been acknowledged that in some contexts, sentences like the otherwise impossible (3a) are felicitous (cf. Inoue 1979; Portner 2003):

\footnotetext{
31 It is difficult to imagine that a clash with another maxim-for instance, the second maxim of quality "do not say that for which you lack adequate evidence" - should be able to balance the violation of the first maxim of quantity. After all, the speaker did not go for the default form, so there must be some reason for that.
} 

a. A: Which Nobel Prize Laureates have visited Princeton? ${ }^{32}$
B: Let's see... Einstein has (visited Princeton), Friedman has (visited Princeton) ...
b. Shakespeare has influenced every known writer to some extent.

This state of fact can be accounted for rather straightforwardly in the pragmatic proposal. By using the marked present perfect in a language like English or Spanish, the speaker would make a strong statement about the existence of a perfect state at the moment of utterance-the use of the default, simple past tense, would not exclude the possibility that there was some current relevance of the event involved. However, the non-existence of the subject of the sentence makes it more difficult for the addressee to know what could be the perfect state associated with the event.

Such a view of life-time effects seems to be supported by the fact that they are not entirely absent from languages like French or German; as Anita Mittwoch observed (p.c.), they are merely not triggered by the present perfect alone. Some additional element, like the adverbial now, is needed in order to make the perfect state more salient: ${ }^{33}$

a. \#J' ai visité maintenant le World Trade Center.
I have visited now the WTC.
'Now, I have visited the World Trade Center.'
b. J' ai visite maintenant le pont Golden Gate.
I have visited now the bridge GG.
'Now, I have visited the Golden Gate bridge.'

\footnotetext{
32 Example cited from (Portner (2003, p. 464).

33 A reviewer questioned whether the examples in (36) and (37) really show what they are supposed to show, and proposes an alternative explanation: since at least German jetzt allows for uses where it refers to times immediately before the moment of utterance, it might be that jetzt localises the event-argument directly, and not the running time of the perfect state. The infelicity of such sentences would then be due to the fact that the destruction of the WTC is simply too far away in the past.

I do not think that this is a possible explanation. Crucially, I do think that one must admit that jetzt makes it impossible to get rid of the perfect state at the moment of utterance, contrary to elements like just which merely seem to localise an event close to the moment of reference. The following contrast is telling:
}
(i) a. Hans hat die Hose gerade ausgezogen, aber er hat sie sofort H. has thepants just taken off, but he has them immediately
'Hans has now taken off his pants, but he immediately put them on again.'

With gerade (the German equivalent of just), one can negate that the result state Hans wears no pants holds, but this is not possible with now. I think that one has to conclude from these examples that the mere localisation of the event immediately before the moment of utterance cannot be responsible for the infelicity of (ib), nor of (36) or (37). 

a. \#Ich hab jetzt das World Trade Center besucht. I have now the WTC visited.
b. Ich hab jetzt die Golden Gate Bridge besucht. I have now the GGB visited.

(36a) and (37a) are unacceptable at a time when there is no World Trade Center, like at the moment of writing of this paper. (36b) and (37b) show that we have indeed a life-time effect, as the same sentence is completely normal when an existing building is mentioned.

Note that the life-time effects in sentences like (36a) and (37a) are rather peculiar: life-time effects in English present perfects are restricted to the subject-position of the sentence, as shown in (38):
a. \#Einstein has visited Princeton.
b. Princeton has been visited by Einstein.

However, the life-time effects in German are not restricted to the object position: if the subject is dead or non-existing, the sentence is bad as well (cf. (39a)). When both subject and object denotatum are no longer existing, the sentence is odd as well (cf. (39b)):
a. \#Einstein hat Princeton jetzt besucht.
Einstein has Princeton now visited.
b. \#Einstein hat das World Trade Center jetzt besucht. Einstein has the WTC now visited.

The life-time effects induced by now and the present perfect seem thus to be considerably stronger than the life-time effects associated with the mere present perfect in languages like English.

\subsection{Perspectives on grammaticalisation}

Let us now turn to an issue related to the preceding discussion: can we extract some predictions on the direction of grammaticalisation from the pragmatic inferences we have described in the last few sections? I would like to argue that we can.

Cross-linguistically, it is very common to see a past tense form, which at some period was the only one-step past-referring tense, put under pressure from a form that started out as a resultative, and subsequently evolved into a present perfect. As time goes by, the present perfect form often becomes more and more past-tense like, and eventually ousts the ancient simple past form from all its uses. This is a tendency which has been observed by Meillet (1912/1982) in a variety of IndoEuropean languages. More recent typological investigations (cf. Bybee et al. 1994; Bybee and Dahl 1989) have shown this tendency to go widely beyond the IndoEuropean realm of languages. A theory of the cross-linguistic variation of present 
perfects and simple pasts should ideally have something to say about this oftenattested tendency of present perfects to become more and more 'past-like'.

Traditionnally, the restrictions of the English and Spanish present perfects are seen as indications that these tense-forms have not yet acquired a past-tense-like status as have their French and German equivalents. However, as we have seen, from the point of view of compositional semantics, these restrictions do not seem to provide clear indications as to what should belong to the core-meaning of the PERFECT-feature, and what should not.

The explanations I have developed in Sect. 4.3 seem to indicate that the restrictions related to the present perfect are 'lighter' in the sense that they can be circumvented by a cooperative speaker, provided that there exists some robust consequence of the event under discussion for the moment of utterance.

The restrictions on the simple past tense in languages like French or German seem however to be more strict, because they do not seem to be 'floutable' in the same way as are the restrictions on the present perfects. Therefore, one should expect that the restrictions against the use of the simple past tense should be quite stable, once the present perfect tense has become the default form. Crucially, there does not seem to be much danger of what one might call a "markedness-swap": the simple past tense should not be able to gradually acquire more and more uses, and become the unmarked and default form.

However, one can expect the situation to be less stable as long as the simple past tense is the default tense. The present perfect can be used, even in contexts where it should be dispreferred, in order to bring about a pragmatic effect of insistence on the perfect state holding at the moment of utterance. In oral speech, it is to be expected that more occurrences than not of a past event have some immediate consequence at the time of utterance, and may therefore qualify for the introduction of a perfect state. Through priming, this may reverse the markedness-relation of the present perfect and simple past tense, and so, the present perfect can become the default one-step past-referring tense.

Along such lines one might also try to explain the growing marginalisation of the simple past tense, which leads eventually to its disappearance. If most events in oral speech have some immediate consequence for the moment of speech, it will happen rather rarely in common speech that one is obliged to signal the non-existence of any particular link of the event under discussion with the moment of utterance (as should be the case for the simple past tense in languages like French and German, according to our discussion). Therefore, such forms should be rather infrequent, and one may reach a degree where first language learners do not get enough input to master the form. In standard French, one might be at such a (terminal) stage of the development in the simple past tense, because it has entirely disappeared from oral language and is restricted to specific forms of written language.

\section{Conclusion}

In this paper, I have shown that the restrictions against the use of the present perfect in languages like English and Spanish are strong tendencies, but that counterexamples 
are attested in corpora. Therefore, I argue that the cause of the restriction cannot be rooted in compositional semantics or in syntax.

I have shown that languages like French and German, where the present perfect is quite unrestricted in use, show restrictions with respect to the use of the simple past tense. The characterisation of this restriction has been argued to involve a notion of "current relevance", where the use of the simple past tenses in French and German implicates the lack of such current relevance.

I have argued that the restrictions of the present perfects in English and Spanish, as well as the restrictions of the simple past tense in French and German, are consequences of the competition between these one-step past-referring tenses. Assuming that compositional semantics are not the locus of cross-linguistic variation, I have proposed a pragmatic analysis for the observed diversity. This pragmatic analysis makes crucial use of the notion of a "marked" form which is opposed to a default form. I have argued that in English and Spanish, the simple past tense is the default form, whereas in French and German, the present perfect is the default form.

The pragmatic analysis developed here accounts for the restrictions observed, and also explains in which case some of these restrictions can be flouted, to achieve special effects.

Some questions however remain open to further research. In order to account cross-linguistically for the distribution of present perfects and simple past tenses, more parameters than the existence or absence of a perfect state must be taken into account. Certainly, evidentiality is among the most important of these parameters. While I am confident that the pragmatic reasoning presented in this article could deal with additional parameters, the integration has not yet been attempted.

Finally, future research will have to inquire more closely whether and how-with the mere assumption of a default and a non-default form-one can obtain more than two possible states of affairs for the distribution of present perfect vs. simple past tenses. The distribution of the simple past of present day French does not correspond exactly to the distribution of the simple past of present day German, nor do the simple past and present perfect of present day French distribute as they did during the 17th century with the famous rule "of 24 hours" for the use of the present perfect (cf. Arnauld and Lancelot 1754). Probably, a more fine-grained notion of 'defaulting' will be needed in order to account for these language states. Gametheory might provide the right tools for such an undertaking.

Acknowledgement I would like to thank Nora Boneh Bridget Copley, Hamida Demirdache Wolfgang Klein, Brenda Laca, Clive Perdue, Kjell Johan Sæbø and the anonymous reviewers of Linguistics and Philosophy for their encouragements, comments and suggestions, which contributed to improve the paper. I am also indebted to Andrew Woodard and Jules Gouguet for helping me with my English. None of the above should be assumed to agree with my positions; all errors and omissions are mine.

\section{References}

Alexiadou, A., Rathert, M., \& von Stechow, A. (Eds.) (2003). Perfect explorations. Berlin: Mouton de Gruyter. 
Arnauld, A., \& Lancelot, C. (1754). Grammaire générale et raisonnée. Paris: Prault fils l'aîné, Available at http://gallica.bnf.fr.

Benveniste, E. (1966/1974). Problèmes de linguistique générale I + II. Paris: Gallimard.

Burgos, D. (2004). Anteriority marking in British English, standard German and Argentinean Spanish. An empirical examination with special emphasis on temporal adverbials. Lincom.

Bybee, J., \& Dahl, O. (1989). The creation of tense and aspect systems in the languages of the world. Studies in Language, 13(1), 51-103.

Bybee, J., Perkins, R., \& Pagliuca, W. (1994). The evolution of grammar. Tense, aspect and modality in the languages of the world. Chicago: University of Chicago Press.

Dahl, O. (1985). Tense and aspect systems. Oxford: Blackwell.

de Swart, H. (1998). Aspect shift and coercion. Natural Language and Linguistic Theory, 16(2), 347-385.

Giorgi, A., \& Pianesi, F. (1997). Tense and aspect. From semantics to morphosyntax. New York: Oxford University Press.

Grice, H. P. (1975). Logic and conversation. In P. Cole \& J. L. Morgan (Eds.), Syntax and semantics. Speech acts (Vol. 3, pp. 41-58). New York: Academic Press.

Inoue, K. (1979). An analysis of the English present perfect. Linguistics, 17, 561-589.

Kamp, H., \& Reyle, U. (1993). From discourse to logic. Introduction to modeltheoretic semantics of natural language, formal logic and discourse representation theory. Dordrecht: Kluwer.

Klein, W. (1992). The present perfect puzzle. Language 68, 525-552.

Klein, W. (2000). An analysis of the German Perfekt. Language, 76(2), 358-382.

Kratzer, A. (1998). More structural analogies betweens pronouns and tenses. In D. Strolovitch \& A. Lawson (Eds.), Proceedings of Salt 8. Ithaca: CLC Publications.

Levinson, S. C. (2000). Presumptive meanings. The theory of generalized conversational implicature. Cambridge: MIT Press.

Lindgren, K. B. (1957). Über den Oberdeutschen Präteritumschwund (Annales Academi Scientiarum Fennica 112). Helsinki: Suomalainen Tiedeakatemia.

Maurice, W. (1935). Discrimination between past and present. Neuphilologische Monatsschrift 6, 312330.

McCoard, R. W. (1978). The English perfect: Tense-choice and pragmatic inferences. Amsterdam: North Holland.

Meillet, A. (1912/1982). L'évolution des formes grammaticales. In Linguistique historique et linguistique générale (pp. 130-148). Genève/Paris: Slatkine/Champion.

Müller, S. (2005). Zur Analyse der scheinbar mehrfachen Vorfeldbesetzung. Linguistische Berichte, 203, 297-330.

Musan, R. (2002). The German perfect. Its semantic composition and its interaction with temporal adverbials. Dordrecht: Kluwer.

Nishiyama, A., \& Koenig, J.-P. (2004). What is a perfect state? In B. Schmeiser, V. Chand, A. Kelleher, \& A. Rodriguez (Eds.), WCCFL 23 Proceedings (pp. 101-113). Somerville: Cascadilla Press.

Pancheva, R., \& von Stechow, A. (2004). On the present perfect puzzle. Ms, University of Southern California and Universität Tübingen.

Portner, P. (2003). The (Temporal) semantics and (Modal) pragmatics of the perfect. Linguistics and Philosophy 26, 459-510.

Rathert, M. (2001). Anteriority versus extended now: theories of the German perfect. In Audiatur Vox Sapientiae. A Festschrift for Arnim von Stechow (pp. 410-426). Berlin: Akademie Verlag.

Reichenbach, H. (1947/1966). Elements of symbolic logic. Toronto: Collier-MacMillan.

Rothstein, B. (2006). The perfect time span. On the present perfect in German, Swedish and English. $\mathrm{Ph} . \mathrm{D}$. thesis, Universität Stuttgart.

Weinrich, H. (1986). Grammaire textuelle du français. Paris: Alliance Française.

Weinrich, H. (1993). Textgrammatik der deutschen Sprache. Mannheim: Duden. 